\title{
Negative regulation of signal transducer and activator of transcription-3 signalling cascade by lupeol inhibits growth and induces apoptosis in hepatocellular carcinoma cells
}

K S Siveen ${ }^{1,8}$, A H Nguyen ${ }^{1,8}, \mathrm{~J} \mathrm{H} \mathrm{Lee}^{2,8}, \mathrm{~F} \mathrm{Li}^{1}$, S S Singh ${ }^{1,3}$, A P Kumar ${ }^{1,3,4,5}$, G Low ${ }^{3,6}, \mathrm{~S} \mathrm{Jha}^{3,6}$, V Tergaonkar $^{7}$, K S Ahn ${ }^{\star}, 2$ and G Sethi ${ }^{*}, 1,3$

${ }^{1}$ Department of Pharmacology, Yong Loo Lin School of Medicine, National University of Singapore, Singapore 117597, Singapore; ${ }^{2}$ Department of Pathology, College of Korean Medicine, Kyung Hee University, Seoul 130-701, Republic of Korea; ${ }^{3}$ Cancer Science Institute of Singapore, Centre for Translational Medicine, 14 Medical Drive, Singapore 117599, Singapore; ${ }^{4}$ Biomedical Sciences, Faculty of Health Sciences, Curtin University, Perth, Western Australia 6009, Australia; ${ }^{5}$ Department of Biological Sciences, University of North Texas, Denton, TX 76203, USA; ${ }^{6}$ Department of Biochemistry, Yong Loo Lin School of Medicine, National University of Singapore, Singapore 117597, Singapore and 'Institute of Molecular and Cell Biology, A*STAR, Biopolis Drive Proteos, Singapore, Singapore

Background: Constitutive activation of signal transducer and activator of transcription signalling 3 (STAT3) has been linked with survival, proliferation and angiogenesis in a wide variety of malignancies including hepatocellular carcinoma (HCC).

Methods: We evaluated the effect of lupeol on STAT3 signalling cascade and its regulated functional responses in HCC cells.

Results: Lupeol suppressed constitutive activation of STAT3 phosphorylation at tyrosine 705 residue effectively in a dose- and time-dependent manner. The phosphorylation of Janus-activated kinases (JAKs) 1 and 2 and Src was also suppressed by lupeol. Pervanadate treatment reversed the downregulation of phospho-STAT3 induced by lupeol, thereby indicating the involvement of a phosphatase. Indeed, we observed that treatment with lupeol increased the protein and mRNA levels of SHP-2, and silencing of SHP-2 abolished the inhibitory effects of lupeol on STAT3 activation. Treatment with lupeol also downregulated the expression of diverse STAT3-regulated genes and decreased the binding of STAT3 to VEGF promoter. Moreover, the proliferation of various HCC cells was significantly suppressed by lupeol, being associated with substantial induction of apoptosis. Depletion of SHP-2 reversed the observed antiproliferative and pro-apoptotic effects of lupeol.

Conclusions: Lupeol exhibited its potential anticancer effects in HCC through the downregulation of STAT3-induced pro-survival signalling cascade.

Hepatocellular carcinoma (HCC) is the most common tumour that originates in the liver, accounting for $70 \%$ to $85 \%$ of the total liver cancer burden worldwide. It has great heterogeneity with respect to tumour behaviour and disease of the underlying liver, and primarily develops from chronic infections caused by hepatitis B and hepatitis $C$ viruses, alcoholic injury and to a lesser extent from genetically determined disorders such as haemochromatosis (Jemal et al, 2011; Baffy et al, 2012). Untreated HCC has an extremely poor prognosis, with a median survival of 1-8 months and a 5-year survival of $\sim 3 \%$ (Cormier et al, 2006). Existing treatment options

*Correspondence: Dr KS Ahn; E-mail: ksahn@khu.ac.kr or Dr G Sethi; E-mail: phcgs@nus.edu.sg
${ }^{8}$ These authors contributed equally to this work.

Revised 23 June 2014; accepted 3 July 2014; published online 7 August 2014

(c) 2014 Cancer Research UK. All rights reserved 0007 - 0920/14 
including surgical resection and use of chemotherapy and/or radiotherapy are commonly associated with severe side effects, and are also limited by therapeutic resistance and disease recurrence (Cervello et al, 2012; Subramaniam et al, 2013). Hence, identification of novel agents that are nontoxic and efficacious is urgently required for both prevention and treatment of HCC.

The signal transducer and activator of transcription signalling 3 (STAT3) protein belongs to the STAT family of transcription factors that are activated in response to cytokines and growth factors (Ihle, 1996). Ligand-dependent activation of STAT regulatory cascades is involved in the regulation of a variety of critical functions, including cell differentiation, proliferation, apoptosis, angiogenesis, metastasis and immune responses (Wang et al, 2011). The abnormal activation of STAT proteins is frequently associated with unrestricted cell growth and malignant transformation (Grivennikov and Karin, 2010). Most of the major human malignancies as well as tumourderived cell lines have been reported to contain constitutively activated STAT proteins, especially STAT3 (Johnston and Grandis, 2011). The STAT3 has been classified as an oncogene because the constitutively active STAT3 can mediate oncogenic transformation in cultured cells and tumour formation in nude mice (Burke et al, 2001). The STAT3 and NF- $\kappa$ B are two major transcription factors regulating the ability of pre-neoplastic and malignant cells to resist tumour surveillance, and the inflammatory milieu promoted by these proteins is one of the key properties that tumours must acquire for transformation (Dey et al, 2008; Ghosh et al, 2012). Activation of STAT3 provides a growth advantage to tumour cells, allowing accumulation, and also confers resistance to conventional therapies that rely on apoptotic machinery to eliminate tumour cells (Rajendran et al, 2012; Subramaniam et al, 2013). Thus, pharmacological modulation of STAT3 protein can be considered as an attractive strategy for cancer prevention and treatment.

One major source of pharmacological inhibitors of STAT3 are agents derived from natural sources, as $\sim 70 \%$ of all anticancer drugs being used in clinical therapy are isolated from natural sources or bear a close structural relationship to compounds of natural origin (Newman, 2008). In the present study, we have investigated for the first time the effect of lupeol (Lup-20(29)-en-3H-ol), a naturally occurring dietary pentacyclic triterpene found in a variety of fruits, vegetables and medicinal plants, on STAT3 signalling cascade in HCC cells. The quantification studies have shown that lupeol is present in a significant quantity in olives $\left(3 \mu \mathrm{gg}^{-1}\right)$, mangoes ( $1.80 \mu \mathrm{g}$ per pulp), aloe leaf ( $280 \mu \mathrm{g}$ per dry leaf), elm plant $(800 \mu \mathrm{g}$ per bark), Japanese pear $(175 \mu \mathrm{g}$ per g twig bark) and ginseng oil (15.2 mg per $100 \mathrm{~g}$ of oil) (Siddique et al, 2011). Lupeol has exhibited strong antioxidant, anti-inflammatory, antiarthritic, antimutagenic and antimalarial activities in several previously reported in vitro and in vivo studies (Siddique and Saleem, 2011). Lupeol has been shown to exert substantial antitumour effects in multiple tumour cell lines and cancer models (Siddique and Saleem, 2011) and has been found to target $\mathrm{Wnt} / \beta$-catenin signalling in human melanoma cells (Tarapore et al, 2010), sensitise castrationresistant prostate cancer cells to antihormone therapy (Siddique et al, 2011), induce apoptosis in head and neck squamous cell carcinoma by suppressing NF- $\kappa \mathrm{B}$ activation (Lee et al, 2007), inhibit the self-renewal ability of liver tumour-initiating cells (T-ICs) present in both HCC cell lines and clinical samples (Lee et al, 2011b) and induce apoptosis in human epidermoid carcinoma cells through negative regulation of mitochondrial, $\mathrm{Akt} / \mathrm{PKB}$ and $\mathrm{NF}-\kappa \mathrm{B}$ signalling pathways (Prasad et al, 2009).

In the present report, we investigated whether lupeol can mediate its anticancer effects in part through the modulation of the STAT3 activation pathway. We observed that lupeol can indeed negatively regulate both constitutive and inducible STAT3 activation, leading to suppression of proliferation, induction of apoptosis and downregulation of expression of various proliferative, anti-apoptotic and angiogenic gene products in HCC cells.

\section{MATERIALS AND METHODS}

Reagents. Lupeol was obtained from Sigma-Aldrich (St Louis, MO, USA). It was resuspended in warm alcohol and diluted in dimethyl sulphoxide (DMSO) to make $10 \mathrm{~mm}$ stock solution and stored at $4{ }^{\circ} \mathrm{C}$. Further dilution was done in cell culture medium as required. MTT, Tris, glycine, $\mathrm{NaCl}$, SDS and BSA were purchased from Sigma-Aldrich. Fetal bovine serum (FBS), RPMI-1640, 0.4\% Trypan blue vital stain, Lipofectamine 2000 and antibioticantimycotic mixture were obtained from Invitrogen (Carlsbad, CA, USA). Mouse monoclonal antibodies to $\mathrm{Bcl}-\mathrm{xL}, \mathrm{Bcl}-2$, survivin, VEGF and caspase- 9 and rabbit polyclonal antibodies to cyclin D1, MMP-9, SHP-2 (SH-PTP2), Bak, Bax, Bid, caspase-3, PARP and IL-6R $\alpha$ were obtained from Santa Cruz Biotechnology (San Diego, CA, USA). Mouse monoclonal antibodies to STAT3 and caspase-8 and rabbit monoclonal antibodies against phosphoSTAT3 (Tyr 705), phospho-specific Src (Tyr 416), Src, phosphospecific Janus-activated kinase 1 (JAK1; Tyr 1022/1023), JAK1, phospho-specific JAK2 (Tyr 1007/1008), JAK2 and Bid (polyclonal) were purchased from Cell Signaling Technology (Beverly, MA, USA). The siRNA for SHP-2 and scrambled control was obtained from Santa Cruz Biotechnology. Goat anti-rabbit-horse radish peroxidase (HRP) conjugate and goat anti-mouse HRP were purchased from Sigma-Aldrich. LIVE/DEAD viability/cytotoxicity kit was purchased from Molecular Probes, Invitrogen (Carlsbad, CA, USA).

Cell lines. Human hepatocellular carcinoma (HCC) cell lines HepG2 and C3A were obtained from American Type Culture Collection (Manassas, VA, USA). The PLC/PRF5, HUH-7 and Hep3B cells were kindly provided by Professor Kam Man Hui, National Cancer Centre, Singapore. All the HCC cells were cultured in Dulbecco's modified Eagle's medium (DMEM) containing $1 \times$ antibiotic-antimycotic solution with $10 \%$ FBS.

EMSA for STAT3 DNA binding. The STAT3 DNA binding was analysed by electrophoretic mobility shift assay (EMSA) using a ${ }^{32} \mathrm{P}$-labelled high-affinity sis-inducible element (hSIE) probe (5'-CTTCATTTCCCGTAAATCCCTA-AAGCT- $3^{\prime}$ and $5^{\prime}$-AGCT TTAGGGATTTACGGGAAATGA-3') as previously described (Bhutani et al, 2007). Briefly, nuclear extracts were prepared from lupeol-treated cells and incubated with the labelled hSIE probe. The DNA-protein complex formed was separated from free oligonucleotide on $5 \%$ native polyacrylamide gels. To confirm the specificity, competition using 30 -fold excess unlabelled oligonucleotides containing consensus or mutated STAT3 binding sites were added for $20 \mathrm{~min}$ at room temperature, after incubation with the radio-labelled oligonucleotides. The dried gels were visualised, and the radioactive bands were quantitated with a Universal Hood II (Bio-Rad Laboratories, Hercules, CA, USA). For additional information, please refer to Supplementary Materials and Methods.

Statistical analysis. Data are expressed as the mean \pm s.d. In all figures, vertical error bars denote the s.d. The significance of differences between groups was evaluated by Student's $t$-test and one-way analysis of variance (ANOVA) test. A $P$-value of $<0.05$ was considered statistically significant.

\section{RESULTS}

Lupeol inhibits constitutive STAT3 phosphorylation in HepG2 cells. The HepG2 cells have been shown to express constitutive STAT3 activation (Rajendran et al, 2011; Lepiller et al, 2013), and hence we set out to determine whether lupeol could inhibit this activation in these cells. The HepG2 cells were incubated with different concentrations of lupeol for $6 \mathrm{~h}$, and the phosphorylation of 
STAT3 was examined by western blot analysis using antibodies that recognise STAT3 phosphorylation at tyrosine 705. As shown in Figure $1 \mathrm{~B}$, lupeol inhibited the constitutive activation of STAT3 in a dose-dependent manner, with maximum inhibition occurring at $\sim 50 \mu \mathrm{M}$. Lupeol had no effect on the expression of STAT3 protein (Figure 1B, lower panel). We also determined the length of incubation time required for the suppression of STAT3 activation by lupeol. As shown in Figure 1C, the inhibition was time dependent, with complete inhibition occurring at $\sim 6 \mathrm{~h}$, again with no effect on the expression of STAT3 protein (Figure 1C, lower panel).

Lupeol inhibits STAT3 DNA-binding activity in HepG2 cells. The phosphorylation of STAT3 promotes homodimerisation, and the STAT3 dimers translocate to the nucleus, where they bind to specific DNA response elements in the promoter regions of responsive target genes to regulate their transcription (Johnston and Grandis, 2011; Subramaniam et al, 2013). Hence, we determined whether lupeol can suppress DNA-binding activity of STAT3. The EMSA analysis of nuclear extracts prepared from HepG2 cells showed that lupeol caused a decrease in STAT3 DNA-binding activity in a dose- (Figure 1D) and time-dependent manner (Figure 1E). Addition of excess unlabeled oligonucleotide (competitor; 30-fold molar excess) caused a complete disappearance of the band, whereas mutated oligonucleotide had no effect on DNA binding (Figure 1F).

Lupeol reduces nuclear pool of STAT3 in HCC cells. As nuclear translocation is central towards the functional activity of transcription factors such as STAT3 (Subramaniam et al, 2013), we determined whether lupeol can suppress nuclear translocation of STAT3. Figure 1F clearly demonstrates that lupeol inhibited the translocation of STAT3 to the nucleus in HepG2 cells.

Lupeol suppresses constitutive activation of c-Src. Signal transducer and activator of transcription signalling 3 has also been reported to be activated by soluble tyrosine kinases of the Src kinase families (Yu et al, 1995; Subramaniam et al, 2013). Hence, we determined the effect of lupeol on constitutive activation of Src kinase in HepG2 cells. We found that lupeol suppressed the constitutive phosphorylation of c-Src kinases (Figure 2A). The levels of nonphosphorylated Src kinases remained unchanged under the same conditions.

Lupeol suppresses constitutive activation of JAK1 and JAK2. Because JAKs phosphorylate STAT proteins when activated by signals from interleukins and other cytokines (Subramaniam et al, 2013), we next analysed whether lupeol can affect constitutive activation of JAK1 in HepG2 cells. We found that lupeol suppressed the constitutive phosphorylation of JAK1 (Figure 2B), with maximum inhibition at $6 \mathrm{~h}$. The levels of nonphosphorylated JAK1 remained unchanged under the same conditions (Figure 2B, bottom panel). To determine the effect of lupeol on JAK2 activation, HepG2 cells were treated for different time intervals with lupeol and phosphorylation of JAK2 was analysed by western blot. As shown in Figure 2C, JAK2 was constitutively active in HepG2 cells and pretreatment with lupeol suppressed this phosphorylation in a time-dependent manner.

Tyrosine phosphatases are involved in lupeol-induced inhibition of STAT3 activation. Several protein tyrosine phosphatases
A

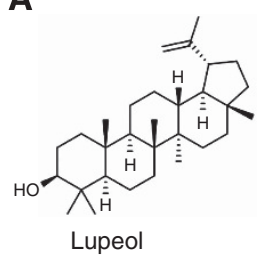

D

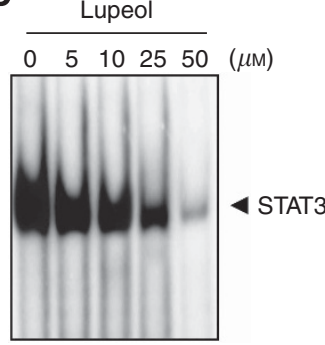

B

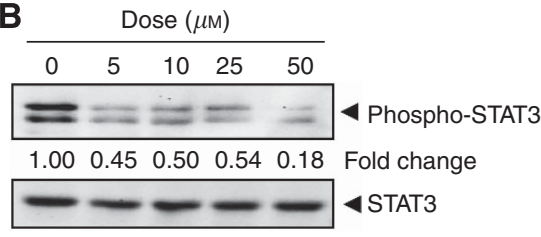

E

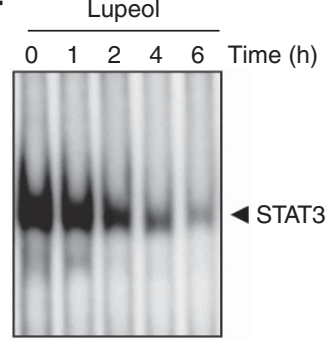

$\mathbf{F}$
C
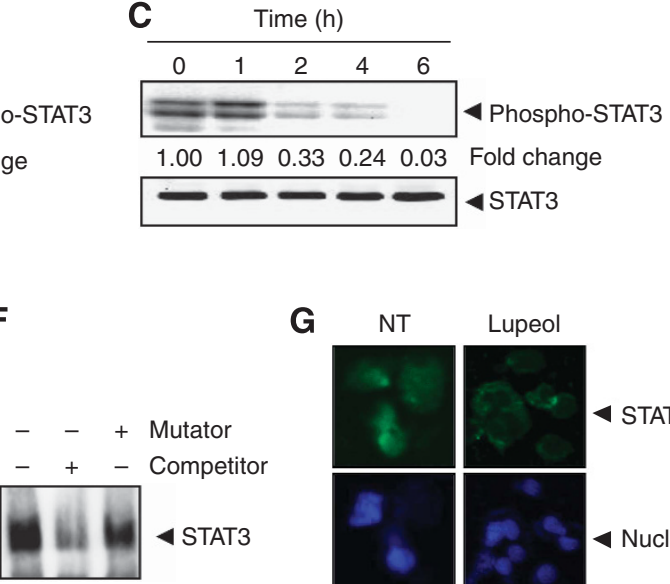

G

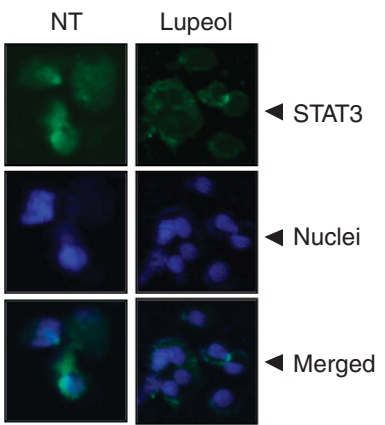

Figure 1. (A) The chemical structure of lupeol. (B) Lupeol suppresses phospho-STAT3 levels in a dose-dependent manner. HepG2 cells $\left(2 \times 10^{6}\right.$ per $\left.\mathrm{ml}\right)$ were treated with the indicated concentrations of lupeol for $6 \mathrm{~h}$, after which whole-cell extracts were prepared and $30 \mu \mathrm{g}$ of protein was resolved on 10\% SDS-PAGE gel, electrotransferred onto nitrocellulose membranes and probed for phospho-STAT3. The same blots were stripped and reprobed with STAT3 antibody to verify equal protein loading. (C) Lupeol suppresses phospho-STAT3 levels in a time-dependent manner. The HepG2 cells $\left(2 \times 10^{6}\right.$ per $\left.\mathrm{ml}\right)$ were treated with the $50 \mu \mathrm{m}$ lupeol for the indicated times, after which western blotting was performed as described in (B). The same blots were stripped and reprobed with STAT3 antibody to verify equal protein loading. (D) Lupeol suppresses STAT3 DNA-binding ability in a dose-dependent manner in HepG2 cells. The HepG2 cells were treated with the indicated concentrations of lupeol for $6 \mathrm{~h}$; nuclear extracts were prepared and analysed by EMSA using the radiolabelled oligonucleotide containing hSIE as described in the Materials and Methods. (E) Lupeol suppresses STAT3 DNA-binding ability in HepG2 cells. The HepG2 cells were treated with $50 \mu \mathrm{m}$ lupeol for indicated time points; nuclear extracts were prepared and analysed by EMSA using the radiolabelled oligonucleotide containing hSIE as described in the Materials and Methods. (F) The EMSA competition assay demonstrating specificity of STAT3 binding. Nuclear extracts of untreated HepG2 cells were prepared and analysed by EMSA using radiolabelled oligonucleotide containing hSIE along with 30-fold excess competitor (an unlabelled oligonucleotide probe) and mutator (an unlabelled probe with a mutation that abrogates STAT3 DNA binding). (G) Lupeol causes inhibition of translocation of STAT3 to the nucleus. The HepG2 cells $\left(1 \times 10^{5}\right.$ per ml) were incubated with or without $50 \mu \mathrm{m}$ lupeol for $6 \mathrm{~h}$ and then analysed for the intracellular distribution of STAT3 by immunocytochemistry. The same slides were counterstained for nuclei with $1 \mu \mathrm{g} \mathrm{ml}{ }^{-1} \mathrm{DAPI}$ for $5 \mathrm{~min}$. The results shown are representative of two independent experiments. 


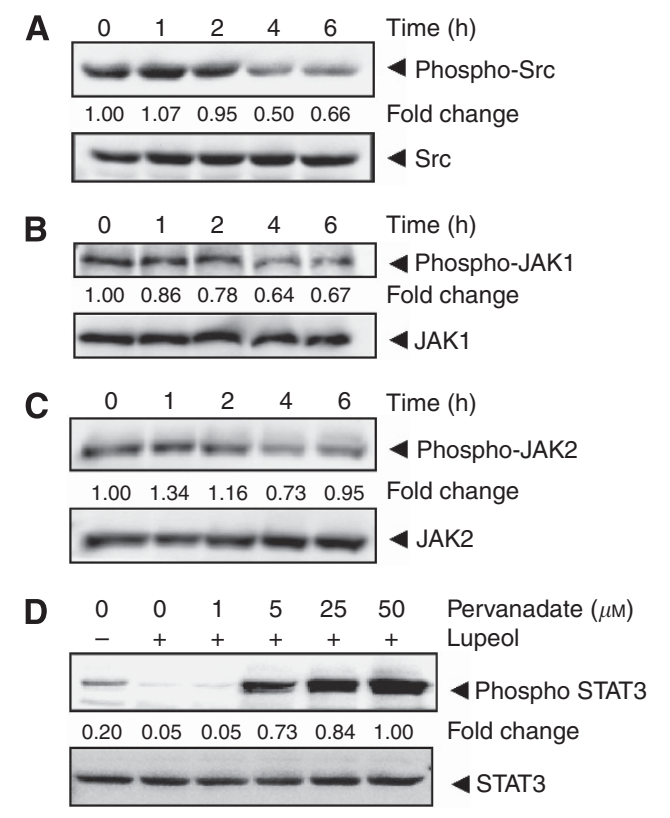

E

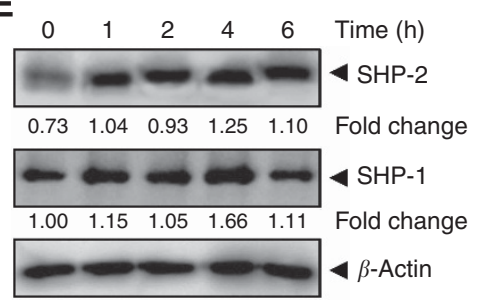

G

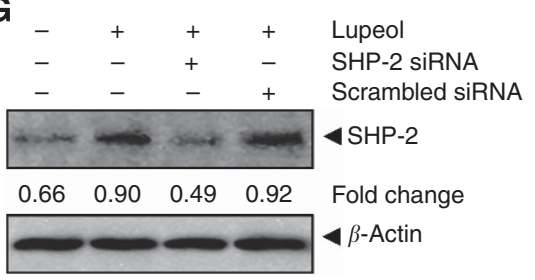

$\mathbf{F}$

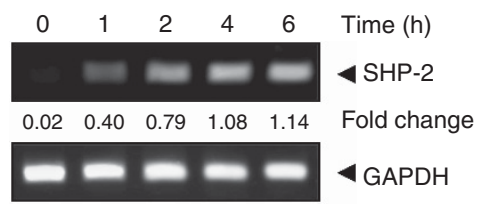

H

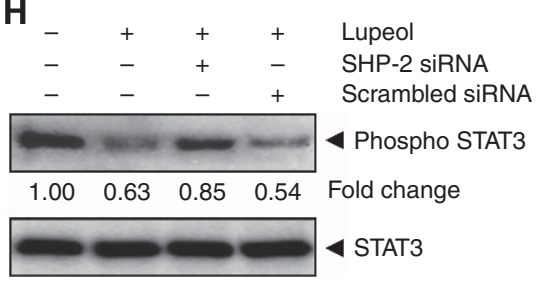

Figure 2. Lupeol inhibits constitutively active STAT3 in HCC cells. (A) Lupeol suppresses phospho-Src levels in a time-dependent manner. The HepG2 cells $\left(2 \times 10^{6}\right.$ per $\left.\mathrm{ml}\right)$ were treated with $50 \mu \mathrm{m}$ lupeol, after which whole-cell extracts were prepared and $30 \mu \mathrm{g}$ aliquots of those extracts were resolved on 10\% SDS-PAGE, electrotransferred onto nitrocellulose membranes and probed for phospho-src antibody. The same blots were stripped and reprobed with Src antibody to verify equal protein loading. (B) Lupeol suppresses phospho-JAK1 levels in a time-dependent manner. HepG2 cells $\left(2 \times 10^{6}\right.$ per $\left.\mathrm{ml}\right)$ were treated with $50 \mu \mathrm{m}$ lupeol for indicated time intervals, after which whole-cell extracts were prepared and $30 \mu \mathrm{g}$ portions of those extracts were resolved on 10\% SDS-PAGE, electrotransferred onto nitrocellulose membranes and probed against phospho-JAK1 antibody. The same blots were stripped and reprobed with JAK1 antibody to verify equal protein loading. (C) Lupeol suppresses phospho-JAK2 levels in a time-dependent manner. The HepG2 cells $\left(2 \times 10^{6}\right.$ per $\left.\mathrm{ml}\right)$ were treated with $50 \mu \mathrm{m}$ lupeol for indicated time intervals, after which wholecell extracts were prepared and $30 \mu \mathrm{g}$ portions of those extracts were resolved on 10\% SDS-PAGE, electrotransferred onto nitrocellulose membranes and probed against phospho-JAK2 antibody. The same blots were stripped and reprobed with JAK2 antibody to verify equal protein loading. (D) Pervanadate reverses the phospho-STAT3 inhibitory effect of lupeol. The HepG 2 cells $\left(2 \times 10^{6}\right.$ per ml) were treated with the indicated concentrations of pervanadate and $50 \mu \mathrm{m}$ lupeol for $6 \mathrm{~h}$, after which whole-cell extracts were prepared and $30 \mu \mathrm{g}$ portions of those extracts were resolved on 10\% SDS-PAGE gel, electrotransferred onto nitrocellulose membranes and probed for phospho-STAT3 and STAT3. (E) Lupeol induces the expression of SHP-2 protein in HepG2 cells. The HepG2 cells were treated with indicated concentrations of lupeol for $6 \mathrm{~h}$, after which western blotting was performed using SHP-2, SHP-1 and $\beta$-actin antibodies. (F) Lupeol induces the expression of SHP-2 in HepG2 cells. The HepG2 cells were treated with indicated concentrations of lupeol for $6 \mathrm{~h}$, after which total RNA was extracted, and the mRNA level of SHP-2 was analysed by RT-PCR. Glyceraldehyde 3-phosphate dehydrogenase (GAPDH) was used as an internal control. (G) Effect of SHP-2 knockdown on lupeol-induced expression of SHP-2. The HepG2 cells were transfected with either SHP-2 siRNA or scrambled siRNA ( $50 \mathrm{~nm}$ ). After $24 \mathrm{~h}$, cells were treated with $50 \mu \mathrm{m}$ lupeol for $6 \mathrm{~h}$ and whole-cell extracts were subjected to western blot analysis. $(\mathrm{H})$ The HepG2 cells were transfected with either SHP-2 siRNA or scrambled siRNA (50 nm). After $24 \mathrm{~h}$, cells were treated with $50 \mu \mathrm{m}$ lupeol for $6 \mathrm{~h}$ and whole-cell extracts were subjected to western blot analysis for phosphorylated STAT3. The results shown are representative of two independent experiments.

(PTPs) have been implicated in the termination of STAT3 signalling, including SHP-2, PTP1B, PTP\&C, TC45 and SHP-1 (Johnston and Grandis, 2011; Subramaniam et al, 2013). To investigate whether lupeol-induced inhibition of STAT3 tyrosine phosphorylation involves activation of any protein tyrosine phosphatase (PTPase), we treated HepG2 cells with the 
broad-acting tyrosine phosphatase inhibitor sodium pervanadate and looked for reversal of lupeol-induced suppression of STAT3 activation (Figure 2D). These data suggest that tyrosine phosphatases may be involved in lupeol-induced inhibition of STAT3 activation in HCC cells.

Lupeol induces the expression of SHP-2 in HCC cells. The SHP-2 is a SH-2 containing tyrosine phosphatase involved in the suppression of a variety of cytokine signals, including STAT3 (Wormald and Hilton, 2004). Hence, we next examined whether lupeol can induce the expression of SHP-2 and SHP-1 in HepG2 cells. The cells were incubated with $50 \mu \mathrm{m}$ lupeol for different time points ranging from 1 to $6 \mathrm{~h}$, and whole-cell extracts were prepared and examined for SHP-2 and SHP-1 protein expression by western blot analysis. As shown in Figure 2E, lupeol significantly induced the expression of SHP-2 protein in HepG2 cells in a timedependent manner, with maximum expression at $4-6 \mathrm{~h}$, whereas it had minimal effect on the expression of SHP-1 protein. The increase in SHP-2 expression by lupeol correlated with downregulation of constitutive STAT3 activation in HepG2 cells (Figure 1C). The two sets of data point to the fact that stimulation of SHP-2 expression by lupeol mediates the downregulation of constitutive STAT3 activation in HepG2 cells. Whether modulation of SHP-2 by lupeol is also regulated at the transcriptional level was investigated as well. For this, cells were incubated with different concentrations of lupeol for $6 \mathrm{~h}$, and then total RNA was extracted, converted to cDNA and examined for SHP-2 gene expression by reverse transcription-PCR (RT-PCR) analysis. As shown in Figure 2F, lupeol induced the expression of SHP-2 mRNA, with maximum expression at 4 to $6 \mathrm{~h}$ of treatment.

SHP-2 siRNA downregulate the expression of SHP-2 induced by lupeol. We determined the effect of SHP-2 siRNA on lupeolinduced SHP-2 expression. As observed by western blot analysis, lupeol-induced SHP-2 expression was effectively inhibited in the cells transfected with SHP-2 siRNA while in the cells treated with the (Figure $2 \mathrm{G}$ ), sequence-randomised scrambled siRNA oligonucleotide no substantial effect was noticed.

SHP-2 siRNA reversed the inhibition of STAT3 activation by lupeol. We next determined whether the suppression of SHP-2 expression by siRNA abrogates the inhibitory effect of lupeol on STAT3 activation. Western blot analysis shows that lupeol failed to suppress STAT3 activation in the cells transfected with SHP-2 siRNA (Figure 2H). However, lupeol caused downregulation of STAT3 activation in cells transfected with scrambled siRNA. These results suggest the pivotal role of SHP-2 in suppression of STAT3 phosphorylation by lupeol.

Lupeol inhibits inducible STAT3, JAK1 and JAK2 phosphorylation in HCC cells. Because IL-6 induces STAT3 phosphorylation, we next determined whether lupeol could inhibit IL-6-induced STAT3 phosphorylation in HCC cells. In Hep3B cells incubated with lupeol for different times, IL-6-induced STAT3, JAK1 and JAK2 phosphorylation was suppressed by lupeol in a timedependent manner. Exposure of cells to lupeol for $4 \mathrm{~h}$ was sufficient to substantially suppress IL-6-induced STAT3 phosphorylation in Hep3B cells (Figure 3A). These results suggest that lupeol can also downregulate inducible STAT3 activation in HCC cells. Moreover, IL-6-induced STAT3 phosphorylation was blocked by neutralising IL- 6 receptor antibodies, thereby indicating the specificity of STAT3 phosphorylation induced by IL-6 in Hep3B cells (Figure 3A, last lane).

Lupeol suppresses EGF-induced STAT3-dependent reporter gene expression in HCC cells. Our above results showed that lupeol inhibited the phosphorylation and nuclear translocation of STAT3. We next determined whether lupeol affects STAT3-
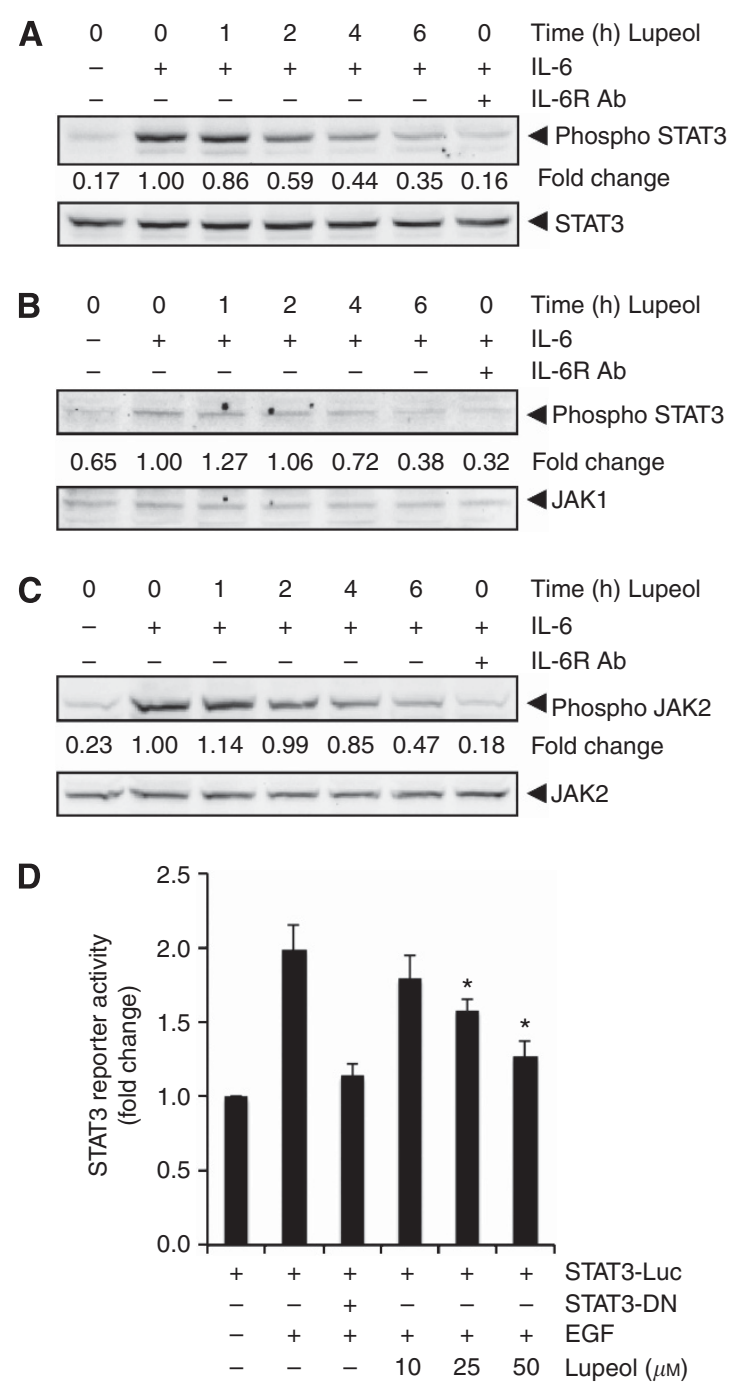

Figure 3. Lupeol downregulates IL-6-induced phospho-STAT3 in HCC cells. (A) The Hep3B cells $\left(2 \times 10^{6}\right.$ per $\left.\mathrm{ml}\right)$ were treated with $50 \mu \mathrm{m}$ lupeol for the indicated times and then stimulated with IL-6 $\left(10 \mathrm{ng} \mathrm{ml}^{-1}\right)$ for $15 \mathrm{~min}$. One set of Hep3B cells were preincubated for $18 \mathrm{~h}$ in the presence of neutralising IL-6 receptor antibody $\left(1 \mu \mathrm{g} \mathrm{ml}^{-1}\right)$ before stimulation with IL-6 to serve as a positive control. Whole-cell extracts were then prepared and analysed for p-STAT3 by western blotting. The same blots were stripped and reprobed with STAT3 antibody to verify equal protein loading. (B) The Hep3B cells $\left(2 \times 10^{6}\right.$ per $\left.\mathrm{ml}\right)$ were treated with $50 \mu \mathrm{M}$ lupeol for the indicated times and then stimulated with IL-6 $\left(10 \mathrm{ng} \mathrm{ml}^{-1}\right)$ for $15 \mathrm{~min}$. One set of Hep3B cells were preincubated for $18 \mathrm{~h}$ in the presence of neutralising IL-6 receptor antibody $\left(1 \mu \mathrm{g} \mathrm{ml}^{-1}\right)$ before stimulation with IL-6 to serve as a positive control. Whole-cell extracts were then prepared and analysed for p-JAK1 by western blotting. The same blots were stripped and reprobed with JAK1 antibody to verify equal protein loading. (C) The Hep3B cells $\left(2 \times 10^{6}\right.$ per $\left.\mathrm{ml}\right)$ were treated with $50 \mu \mathrm{M}$ lupeol for the indicated times and then stimulated with IL-6 $\left(10 \mathrm{ng} \mathrm{ml}^{-1}\right)$ for $15 \mathrm{~min}$. One set of Hep3B cells were preincubated for $18 \mathrm{~h}$ in the presence of neutralising IL-6 receptor antibody $\left(1 \mu \mathrm{g} \mathrm{ml}^{-1}\right)$ before stimulation with IL-6 to serve as a positive control. Whole-cell extracts were then prepared and analysed for p-JAK2 by western blotting. The same blots were stripped and reprobed with JAK2 antibody to verify equal protein loading. (D) The PLC/PRF5 cells $\left(5 \times 10^{5}\right.$ per ml) were transfected with STAT3-luciferase (STAT3-Luc) plasmid, incubated for $48 \mathrm{~h}$ and treated with indicated doses of lupeol for $6 \mathrm{~h}$ and then stimulated with EGF $\left(100 \mathrm{ng} \mathrm{ml}^{-1}\right)$ for $2 \mathrm{~h}$. Whole-cell extracts were then prepared and analysed for luciferase activity. The results shown are representative of two independent experiments. ${ }^{\star} P<0.05$. Abbreviation: $\mathrm{DN}=$ dominant negative. 

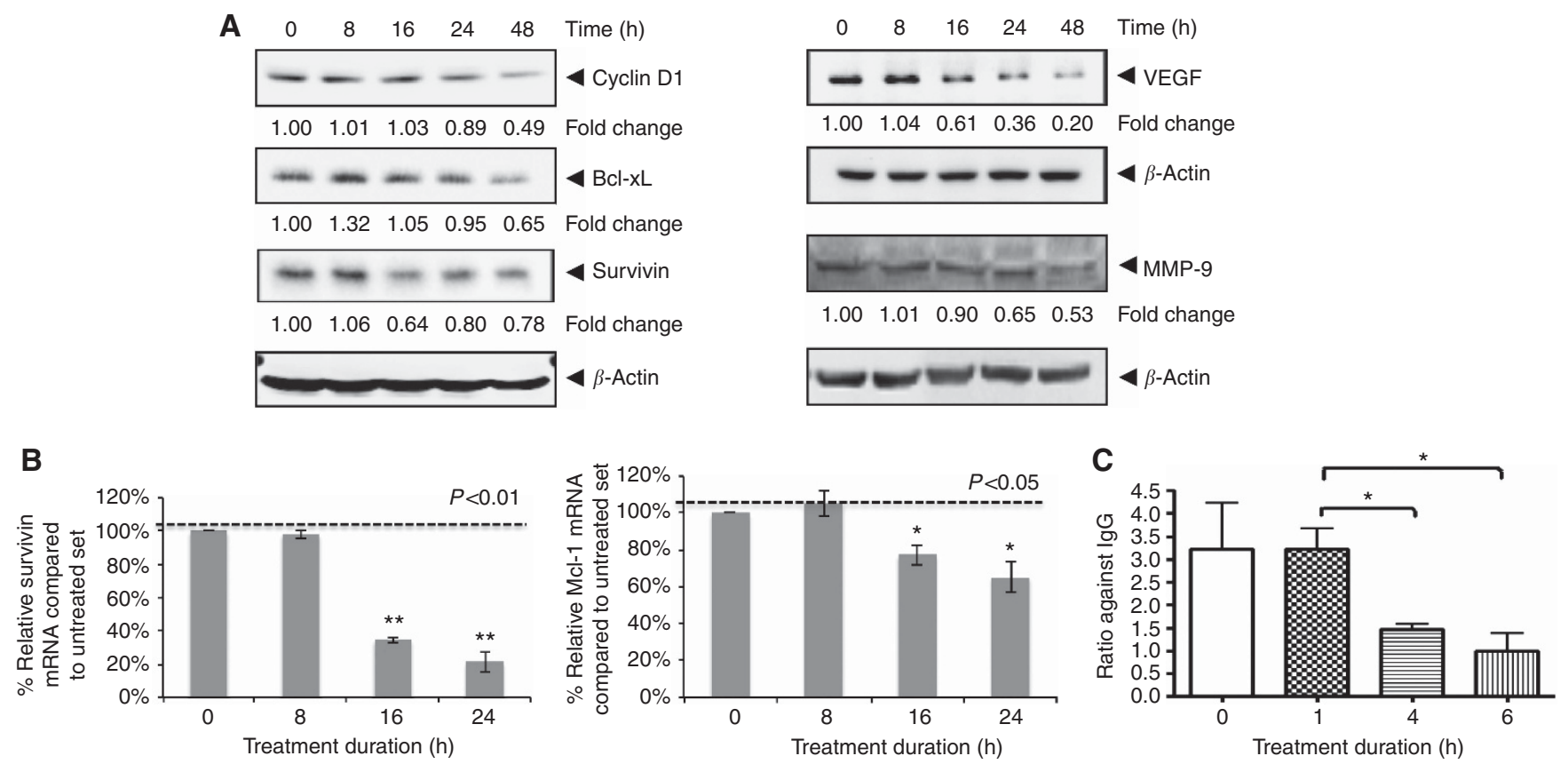

Figure 4. Lupeol suppresses expression of STAT3-regulated gene products involved in proliferation, survival and angiogenesis. (A) The HepG2 cells $\left(2 \times 10^{6}\right.$ per $\left.\mathrm{ml}\right)$ were treated with $50 \mu \mathrm{m}$ lupeol for indicated time intervals, after which whole-cell extracts were prepared and $30 \mu \mathrm{g}$ portions of those extracts were resolved on 10\% SDS-PAGE, membrane sliced according to molecular weight and probed against cyclin D1, Bcl-xL, survivin, VEGF and MMP-9 antibodies. The same blots were stripped and reprobed with $\beta$-actin antibody to verify equal protein loading. The results shown are representative of two independent experiments. (B) The HepG2 cells $\left(3 \times 10^{5}\right.$ per ml) were treated with $50 \mu \mathrm{m}$ lupeol for the indicated time intervals, after which cells were harvested after treatment and RNA samples were extracted. Then, $1 \mu \mathrm{g}$ portions of the respective RNA extracts was used for reverse transcription to generate corresponding cDNA. Real-time PCR was performed to measure the relative quantities of mRNA. Each RT product was targeted against Mcl-1 and survivin probes, with GAPDH as endogenous control for measurement of equal loading of RNA samples. Results were analysed using Sequence Detection Software version 1.3 provided by Applied Biosystems. Relative gene expression was obtained after normalisation with endogenous GAPDH and determination of the difference in threshold cycle (Ct) between treated and untreated cells using 2- $\Delta \Delta \mathrm{Ct}$ method. (C) Treatment with lupeol decreases binding of STAT3 to VEGF promoter. Chromatin immunoprecipitation (ChIP) assay was performed in HepG2 cells to examine binding of STAT3 on VEGF promoter. Cells were treated with lupeol for indicated time and crosslinked. The cell pellets were processed for ChIP as detailed under Supplementary Materials and Methods. Ratio of quantitative real-time PCR signal in STAT3 immunoprecipitate relative to $\operatorname{lgG}$ (negative control) immunoprecipitate is plotted. Mean \pm s.d. of three experiments $\left({ }^{\star} P<0.05\right)$.

dependent gene transcription. When PLC/PRF5 cells transiently transfected with the pSTAT3-Luc construct were stimulated with EGF, STAT3-mediated luciferase gene expression was increased. Transfection with dominant-negative STAT3 blocked this increase, indicating specificity. When the cells were pretreated with lupeol, EGF-induced STAT3 activity was inhibited in a dose-dependent manner (Figure 3D).

Lupeol downregulates the expression of various antiproliferative, anti-apoptotic and angiogenic gene products in HCC cells. The persistently activated STAT3 proteins in tumour cells promote a permanent alteration of various oncogenic genes that control cellular processes such as proliferation, survival, invasion, angiogenesis and chemoresistance (Wang et al, 2011). Treatment of HepG2 cells with lupeol was found to downregulate the expression of the cell cycle regulator (cyclin D1), the antiapoptotic proteins (Bcl-xL, survivin), the angiogenic gene product VEGF and an important matrix metalloproteinase-9 (MMP-9) that is involved in the degradation of cellular matrix, all of which have been reported to be regulated by STAT3. Their expression decreased in a time-dependent manner, with maximum suppression observed at $\sim 48 \mathrm{~h}$ (Figure $4 \mathrm{~A}$ ). We also found that mRNA expression of survivin and $\mathrm{Mcl}-1$ was modulated by lupeol treatment in a timedependent manner, with maximum reduction observed at $\sim 24 \mathrm{~h}$ after treatment (Figure 4B).
Exposure of HCC cells to lupeol decreases binding of STAT3 to VEGF promoter. In order to understand the mechanism of decrease in STAT3-regulated gene expression, we next performed ChIP experiments. For this, lupeol- or vehicle-treated cells were crosslinked at indicated time post lupeol treatment, and in vivo binding of STAT3 was investigated. Treatment with lupeol resulted in a significant decrease in STAT3 binding to VEGF promoter in a time-dependent manner (Figure 4C). These data suggest that upon exposure to lupeol, a decrease in expression of STAT3 target genes is observed because of a decreased STAT3 binding to its promoter.

Lupeol inhibits the proliferation of HCC cells in a dose- and time-dependent manner. As treatment with lupeol was found to downregulate the expression of cyclin D1, a gene involved in cell proliferation, we investigated whether lupeol can inhibit the proliferation of various HCC cells using the MTT assay. Lupeol inhibited proliferation of C3A, HepG2, PLC/PRF5 and HUH-7 cells in a dose- and time-dependent manner (Figure 5A).

Lupeol causes the accumulation of the cells in the sub-G1 phase of the cell cycle. To further confirm that lupeol inhibits proliferation of HCC cells through induction of apoptosis, we analysed cell cycle distribution after PI staining. We found that lupeol increased the accumulation of the cell population in the subG1 phase after treatment for 6,12 and $24 \mathrm{~h}$ in a time-dependent manner, indicative of cellular apoptosis (Figure 5B). 

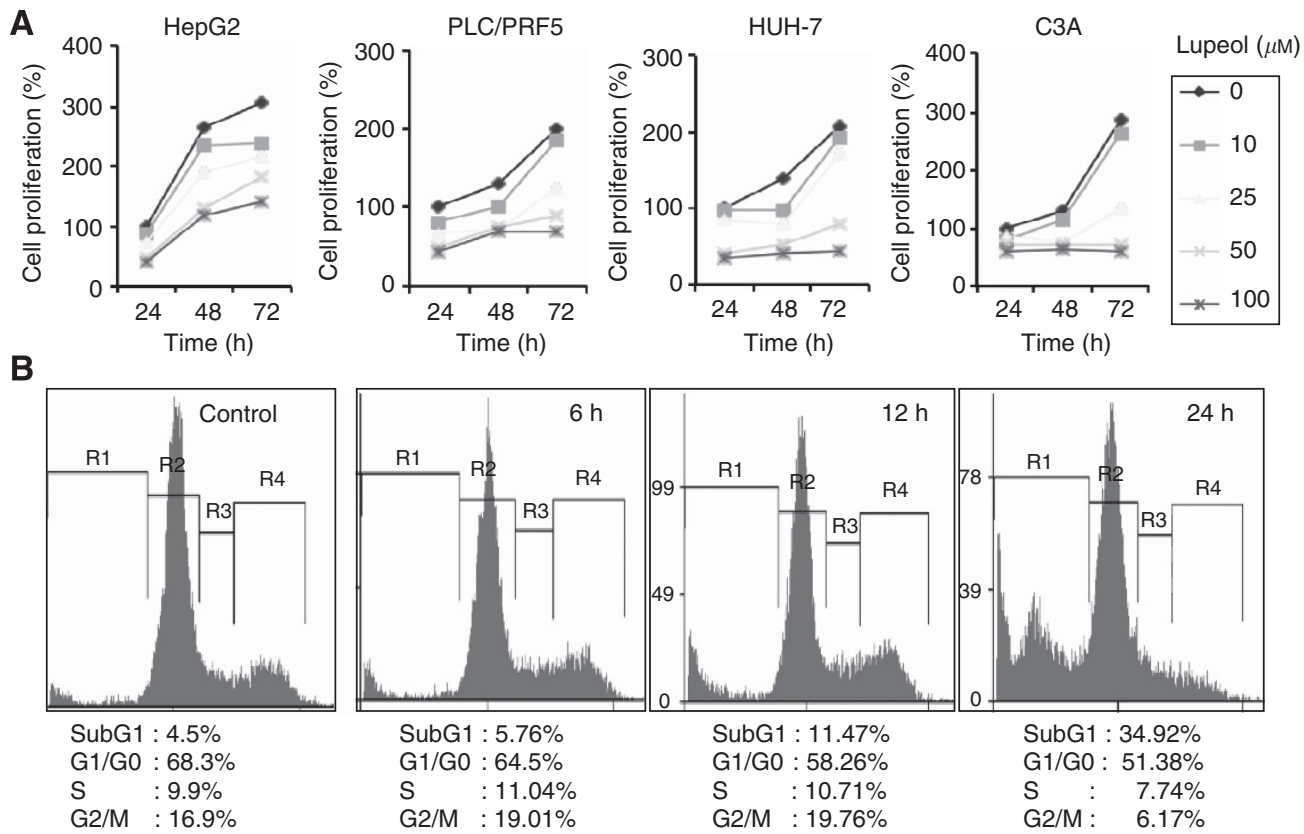

C
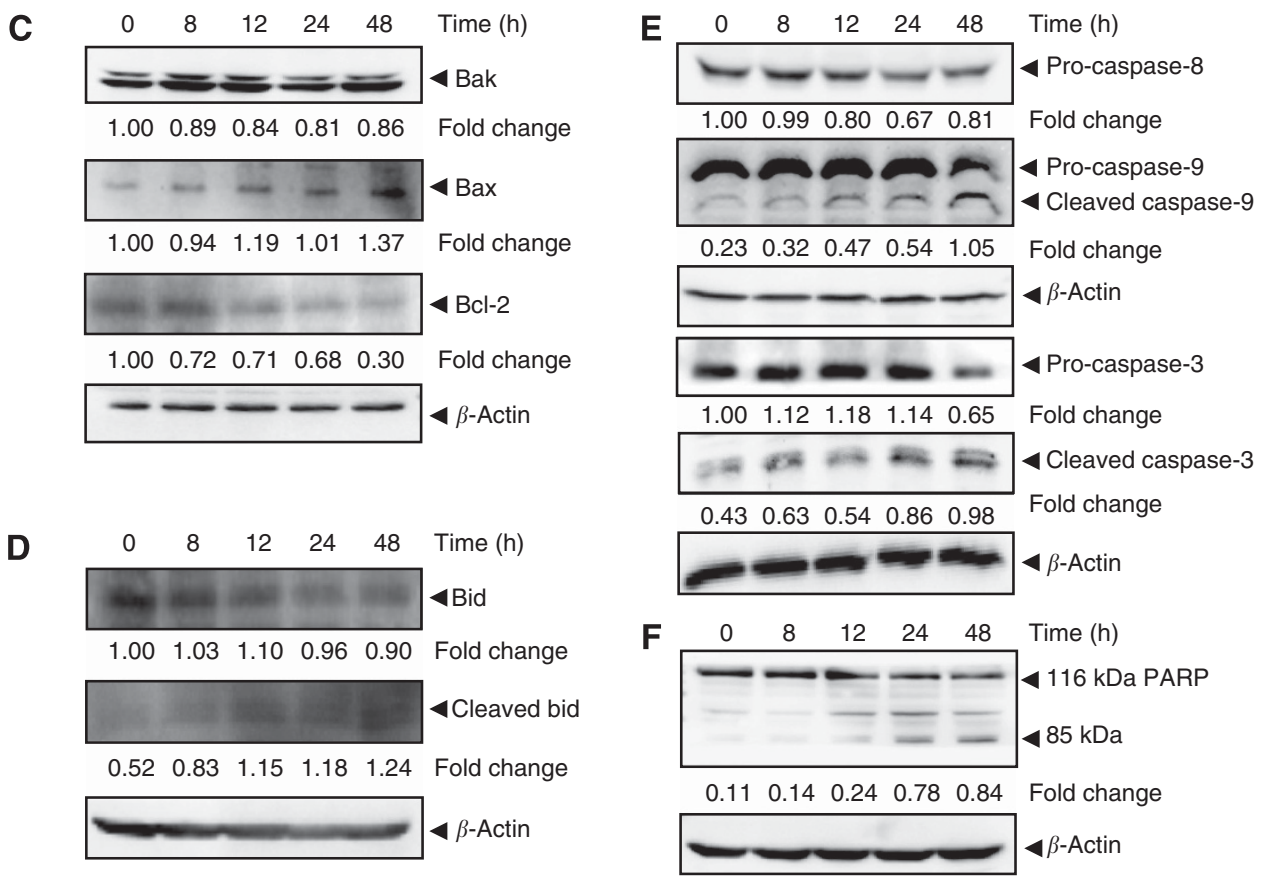

Figure 5. (A) The HepG2, PLC/PRF5, HUH-7 and C3A cells $\left(5 \times 10^{3}\right.$ per ml) were plated in triplicate, treated with indicated concentrations of lupeol and then subjected to MTT assay after 24,48 and $72 \mathrm{~h}$ to analyse proliferation of cells. The s.d. values between triplicates are indicated. (B) The HepG2 cells $\left(2 \times 10^{6}\right.$ per ml) were treated with $50 \mu \mathrm{m}$ lupeol for the indicated times, after which the cells were washed, fixed, stained with PI and analysed for DNA content by flow cytometry. (C) The HepG2 cells were treated with $50 \mu \mathrm{m}$ lupeol for the indicated times, whole-cell extracts were prepared, separated on SDS-PAGE and subjected to western blotting against Bak, Bax and Bcl-2 antibodies. (D) The HepG2 cells were treated with $50 \mu \mathrm{m}$ lupeol for the indicated times, whole-cell extracts were prepared, separated on SDS-PAGE and subjected to western blotting against Bid and cleaved Bid antibodies. The same blots were stripped and reprobed with $\beta$-actin antibody to show equal protein loading. (E) The HepG2 cells were treated with $50 \mu \mathrm{m}$ lupeol for the indicated times, whole-cell extracts were prepared, separated on SDS-PAGE and subjected to western blotting against pro-caspase-8, pro-caspase-9, pro-caspase-3 and cleaved caspase-3 antibodies. The same blot was stripped and reprobed with $\beta$-actin antibody to show equal protein loading. (F) The HepG2 cells were treated with $50 \mu \mathrm{m}$ lupeol for the indicated times, and whole-cell extracts were prepared, separated on SDS-PAGE and subjected to western blot against PARP antibody. The same blot was stripped and reprobed with $\beta$-actin antibody to show equal protein loading. The results shown are representative of two independent experiments.

Lupeol upregulates the expression of Bak and Bax and downregulates Bcl-2. We found that lupeol-treated HepG2 cells had an increase in the expression of the pro-apoptotic proteins Bak and Bax, with maximum upregulation observed at $48 \mathrm{~h}$ (Figure 5C). The expression of another important anti-apoptotic protein, Bcl-2, was also substantially inhibited by lupeol in a timedependent manner (Figure 5C).

Lupeol modulates the expression of Bid. Whether lupeol can modulate the expression of pro-apoptotic protein, Bid, was also 
A

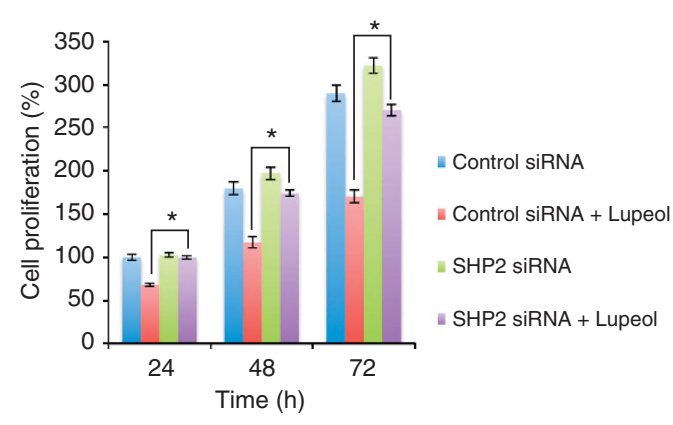

B

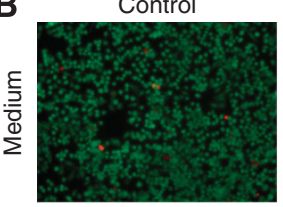

$2.3 \pm 0.4 \%$

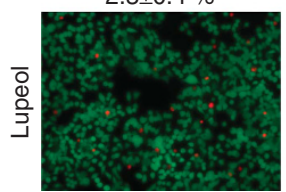

$32.7 \pm 1.6 \%$

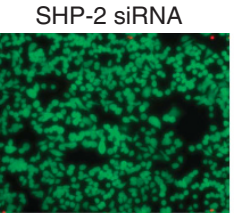

$1.9 \pm 0.3 \%$

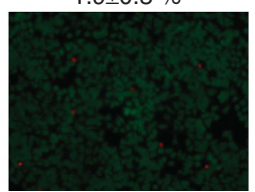

$11.4 \pm 0.7 \%$
Control siRNA

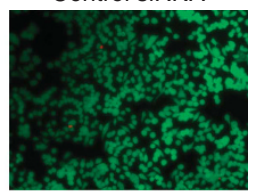

$2.2 \pm 0.4 \%$

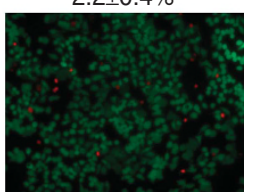

$30.4 \pm 2.1 \%$

C
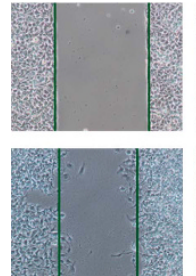

$-$

D
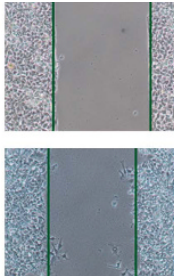

$-$

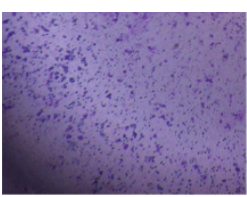

Control

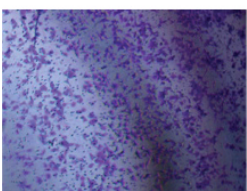

CXCL12

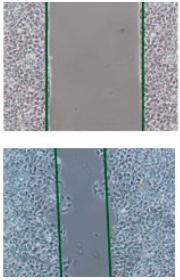

$+$
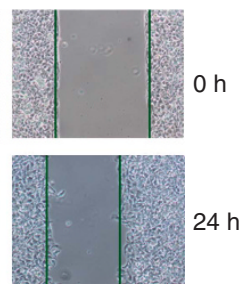

$+\quad$ CXCL12

Lupeol
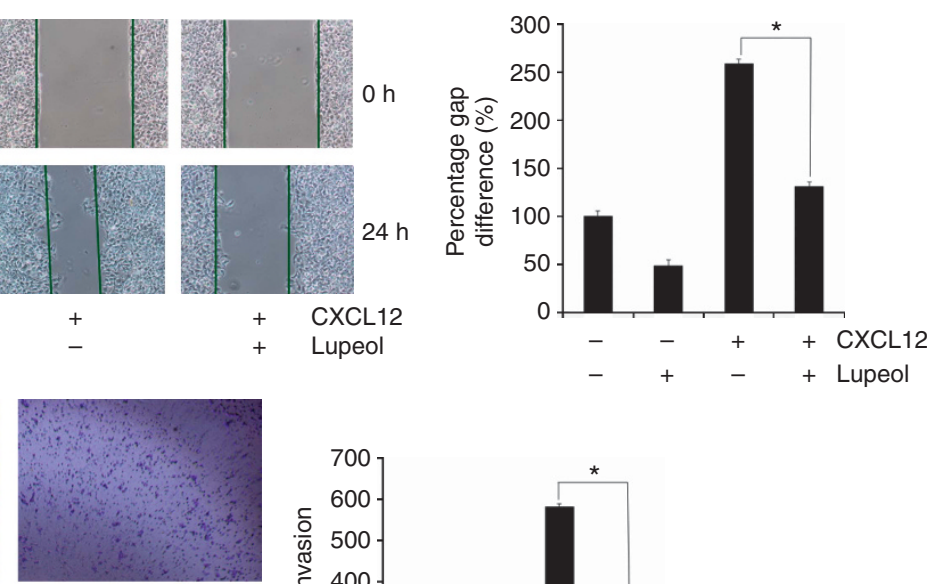

Lupeol

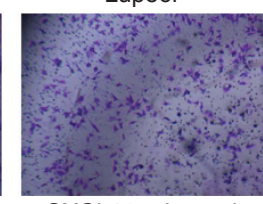

CXCL12 + Lupeol

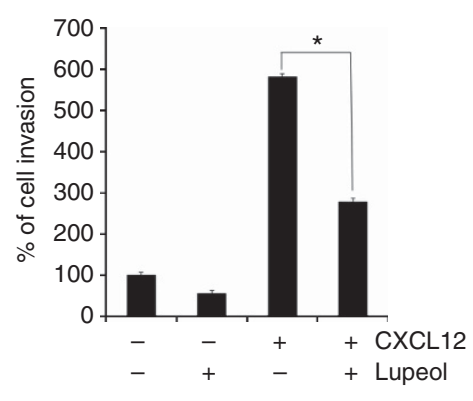

Figure 6. (A) Gene silencing of SHP-2 abolishes lupeol-induced suppression in tumour cell proliferation. The HepG2 cells were transfected with SHP-2 siRNA or control siRNA for $48 \mathrm{~h}$ and then treated with $50 \mu \mathrm{m}$ lupeol for 24,48 and $72 \mathrm{~h}$. Mitochondrial dehydrogenase activity was measured at 24,48 and $72 \mathrm{~h}$ after lupeol treatment. Cell proliferation was analysed by measuring absorbance at $570 \mathrm{~nm}$. ${ }^{\star} \mathrm{P}<0.05$. (B) Silencing of SHP-2 suppresses lupeol-induced apoptosis. The HepG2 cells were transfected with SHP-2 siRNA or control siRNA for $48 \mathrm{~h}$ and treated with $50 \mu \mathrm{M}$ for $24 \mathrm{~h}$. Apoptosis was measured by live/dead assay. Values represent the mean number of apoptotic cells \pm s.d. Magnification $\times 100$. (C) Woundhealing assay for evaluating effect of lupeol on the migration of HepG2 cells. An IBIDI culture insert (IBIDI GmbH) consists of two reservoirs separated by a $500 \mu \mathrm{m}$ thick wall created by a culture insert in a $35 \mathrm{~mm}$ Petri dish. For migration assay, an equal number of HepG 2 cell (70 $\mu$; $5 \times 10^{5}$ cells per ml) were added into the two reservoirs of the same insert and incubated at $37{ }^{\circ} \mathrm{C} / 5 \% \mathrm{CO}_{2}$. After $12 \mathrm{~h}$, the insert was gently removed creating a gap of $\sim 500 \mu \mathrm{m}$. The cells were treated with $50 \mu \mathrm{m}$ lupeol for $12 \mathrm{~h}$ before being exposed to $100 \mathrm{ng} \mathrm{ml}{ }^{-1} \mathrm{CXCL} 12 \mathrm{for} 24 \mathrm{~h}$. Width of wound was measured at time 0 and $24 \mathrm{~h}$ of incubation with and without lupeol in the absence or presence of CXCL12. The representative photographs showed the same area at time 0 and after $24 \mathrm{~h}$ of incubation. (D) Lupeol suppresses invasion of HepG2 cells. The HepG2 cells $\left(2 \times 10^{5}\right.$ cells) were seeded in the top chamber of the Matrigel. After preincubation with or without $50 \mu \mathrm{m}$ lupeol for $12 \mathrm{~h}$, transwell chambers were then placed into the wells of a 24-well plate, in which we had added either the basal medium only or basal medium containing $100 \mathrm{ng} \mathrm{ml}^{-1} \mathrm{CXCL} 12$ in a predetermined arrangement. After incubation for $24 \mathrm{~h}$, cell invasion was analysed and columns represent mean number of invaded cells. $\star P<0.05$.

examined. We found that treatment with lupeol decreased the expression of full-length Bid in a time-dependent manner in HepG2 cells (Figure 5D). In addition, we noticed that lupeol treatment caused an increase in the level of cleaved Bid.

Lupeol activates caspases and induces PARP cleavage in HCC cells. Whether suppression of constitutively active STAT3 in HepG2 cells by lupeol leads to apoptosis was also investigated. In HepG2 cells treated with lupeol, there was a time-dependent activation of the initiator caspases 8 and 9 (Figure 5E). The levels of these pro-caspases were reduced upon treatment with lupeol, with maximum effects observed at $\sim 48 \mathrm{~h}$. There was an increase in the levels of cleaved caspase- 9 that correlated with the decrease in pro-caspase-9 upon treatment with lupeol. There was also a timedependent activation of the effector molecule pro-caspase-3, with a concomitant increase in cleaved form of caspase- 3 in a timedependent manner (Figure 5E). Activation of downstream caspases led to the cleavage of a $118-\mathrm{kDa}$ poly(ADP-ribose) polymerase (PARP) protein into an $85-\mathrm{kDa}$ fragment (Figure $5 \mathrm{~F}$ ). This result clearly suggests that lupeol induces caspase-3-dependent apoptosis in HepG2 cells.

Transfection with SHP-2 siRNA abrogates antiproliferative/ pro-apoptotic effects of lupeol in HCC cells. The effect of silencing of the SHP-2 gene on the antiproliferative effects of lupeol was investigated using HepG2 cells transfected with SHP-2 or 
scrambled siRNA before treatment with lupeol. We found that lupeol decreased the proliferation of cells and that transfection with SHP-2 siRNA reversed the antiproliferative effects of lupeol (Figure 6A). These results suggest that SHP-2 plays a major role in inhibiting tumour cell proliferation through inhibition of STAT3 activation. As we found that lupeol-induced suppression in STAT3 activation was mediated through the induction of SHP-2, we investigated whether silencing of SHP-2 with siRNA can abrogate lupeol-induced apoptosis in HepG2 cells. Apoptosis was analysed through the examination of intracellular esterase activity by live/dead assay. Transfection with SHP-2 siRNA abolished lupeol-induced apoptosis (Figure 6B), and the percentage of apoptotic cells was reduced from $32.7 \%$ to $11.4 \%$, whereas transfection with control siRNA had no significant effect on apoptosis (a decrease from $32.7 \%$ to $30.4 \%$ ).

Lupeol suppresses CXCL12-induced HepG2 cell migration and invasion. Constitutively expressed STAT3 is involved in the expression of MMP-2 and MMP-9 that play a major role in tumour metastasis (Dechow et al, 2004; Li et al, 2006). Hence, whether suppression of constitutively active STAT3 in HepG2 cells by lupeol leads to inhibition in cell migration and invasion was also investigated. Effect of lupeol on HepG2 cell migration was analysed using an in vitro wound-healing assay. We found that HepG2 cells migrated faster under the influence of CXCL12 and this effect was significantly abolished on treatment with lupeol (Figure 6C). Using an in vitro invasion assay, we also found that CXCL12 significantly induced the invasion of HepG2 cells and that lupeol significantly abrogated the invasive activity (Figure 6D).

\section{DISCUSSION}

The pivotal aim of this study was to determine whether lupeol exerts its anticancer effects through the abrogation of the STAT3 signalling pathway in HCC cells. We found that this triterpene suppressed both constitutive and inducible STAT3 activation in human HCC cells in parallel with the inhibition of JAK1, JAK2 and Src activation. Lupeol also downregulated the expression of STAT3-regulated gene products, including cyclin D1, Bcl-2, Bcl$\mathrm{xL}$, survivin, VEGF and MMP-9 proteins. It also caused the inhibition of proliferation, increased accumulation of cells in subG1 phase and significantly attenuated migratory and invasive potential of HCC cells. Aberrant STAT3 activation has been linked to oncogenesis in a variety of human tumours including HCC, and our studies indicate for the first time that lupeol may also exert its anticancer effects through the modulation of STAT3 signalling cascade.

Whether investigated by western blot analysis for STAT3 phosphorylation at tyrosine 705 residue, by nuclear translocation or by EMSA experiments, we noticed that lupeol substantially suppressed STAT3 activation in HCC cells. We found that lupeol also suppressed STAT3 activation induced by IL- 6 , one of the many tumour cell growth factors that activate STAT3 (Bromberg and Wang, 2009). The doses required to inhibit STAT3 activation were more or less comparable to rationally designed pharmacological blockers that inhibit STAT3 dimerisation (Fuke et al, 2007). The inhibitory effects of lupeol on STAT3 phosphorylation correlated with the suppression of activation of upstream protein tyrosine kinases (c-Src, JAK1 and JAK2) in a time-dependent manner in HCC cells. Prior studies have indicated that Src and JAK kinases activities cooperate to mediate constitutive activation of STAT3 in tumour cells (Garcia et al, 2001). Our data also indicate that lupeol may abrogate cooperation of Src and JAKs involved in tyrosyl phosphorylation of STAT3 in HCC cells. The roles of JAKs and Akt have been implicated in IL-6-induced STAT3 activation (Ihle, 1996; Chen et al, 1999). We found that
IL-6-induced STAT3, JAK1 and JAK2 activation was also suppressed by lupeol in HCC cells. We further noticed that lupeol also suppressed nuclear translocation and EGF-induced reporter activity of STAT3. This suggests that this triterpene could manifest its effect on both constitutive and inducible STAT3 activation through multiple mechanism(s). We postulate that STAT3 inhibitory effects of lupeol as reported here can substantially contribute to its previously reported growth inhibitory and apoptotic effects in HCC cells (Baffy et al, 2012). Interestingly, it has been previously documented that lupeol can also target liver tumourinitiating cells through phosphatase and tensin homologue modulation in both HCC cell lines and clinical samples (Lee et al, 2011b). Because $\mathrm{CD}_{2} 4^{+}$liver stem cells can also drive self-renewal and tumour initiation through STAT3-mediated regulation of NANOG gene (Lee et al, 2011a), it is feasible that STAT3 inhibitory effects of lupeol may also mediate its liver stem cell-targeting effects.

The phosphorylation of STAT3 plays a key role in proliferation, survival and angiogenesis of tumour cells (Yue and Turkson, 2009). Diverse types of cancer, including head and neck (Li et al, 2013), multiple myeloma (Kannaiyan et al, 2011), prostate (Shanmugam et al, 2011), breast (Kim et al, 2013) and lymphomas and leukaemias (Zhang et al, 2002), express constitutively active STAT3. The suppression of constitutively active STAT3 in HCC cells by lupeol raises the possibility that this novel STAT3 inhibitor might also target deregulated STAT3 activation in other types of tumour cells. Moreover, it has been reported that lupeol can also abrogate several oncogenic signal transduction cascades including $\mathrm{NF}-\kappa \mathrm{B}, \mathrm{PI} 3 \mathrm{~K} / \mathrm{Akt}$ and $\mathrm{Wnt} / \beta$-catenin in tumour cells (Siddique and Saleem, 2011). Interestingly, it has been found that STAT3 can indeed prolong NF- $\kappa \mathrm{B}$ nuclear retention through acetyltransferase p300-mediated RelA acetylation, thereby interfering with NF- $\kappa$ B nuclear export (Lee et al, 2009). Thus, it is quite feasible that the inhibition of STAT3 activation may also mediate suppression of $\mathrm{NF}-\kappa \mathrm{B}$ signalling by lupeol.

Under normal conditions, both the amplitude and duration of receptor-induced STAT3 activation are tightly controlled by a variety of endogenous protein regulators (Cervello et al, 2012; Subramaniam et al, 2013). Numerous PTPs are involved in the regulation of JAK/STAT signalling, including SHP1, SH-PTP2, CD45, PTP1B, TC-PTP, PTPRT and PTP-BL (Xu and Qu, 2008). The SHP2 is a ubiquitously expressed $\mathrm{SH} 2$ domain-containing PTP. The STATs can be inactivated by SHP-2 in both the cytoplasm and the nucleus (Shuai and Liu, 2003). We found that pervanadate treatment could reverse the lupeol-induced downregulation of STAT3 in HCC cells, thereby possibly suggesting the involvement of a tyrosine phosphatase. Indeed, we noticed that lupeol treatment substantially increased the expression of SHP-2 at both protein and mRNA levels that correlated with downregulation of constitutive STAT3 phosphorylation. Transfection with SHP-2 siRNA reversed the STAT3 inhibitory effect of lupeol, thereby further implicating a critical role of this phosphatase in lupeolinduced abrogation of STAT3 activation. Interestingly, the multikinase protein tyrosine inhibitor sorafenib approved by FDA for the treatment of HCC has also found to act through a similar molecular mechanism and inhibit STAT3 activation through the induction of a phosphatase (Yang et al, 2010).

Once activated in malignant cells, STAT3 can induce the expression of a subset of genes whose products are important. Cancer cells harbouring aberrant STAT3 activity display elevated levels of anti-apoptotic (Bcl-2, Bcl-xL and survivin), cell cycle regulatory proteins (cyclin D1, c-Myc) and invasive/angiogenic gene products (MMP-9 and VEGF) (Page et al, 2011). Moreover, constitutively active STAT3 has been demonstrated to mediate uncontrolled malignant cell proliferation and directly contribute to tumourigenesis (Yue and Turkson, 2009). We analysed the effect of lupeol on proliferation and noticed that this triterpene could significantly suppress growth potential of four different HCC cell 
lines (HepG2, PLC/PRF5, C3A and HUH-7) in a dose- and timedependent manner. The downregulation of cyclin D1 expression by lupeol directly correlated with suppression in proliferation as observed in various HCC cell lines. Constitutive activation of STAT3 contribute to the upregulation of $\mathrm{Bcl}-\mathrm{xL}$ in ovarian cancer cell lines that contributes to the survival advantage of human ovarian carcinoma (Burke et al, 2001). Activation of STAT3 signalling can also induce expression of survivin gene that was found to confer resistance to apoptosis in human breast cancer cells (Gritsko et al, 2006). Hence, tumour cells containing persistently activated STAT3 are more resistant to environmental apoptotic cues and conventional chemotherapies that rely on the apoptotic pathway for chemotherapy-induced cell death. Thus, the downregulation of the expression of $\mathrm{Bcl}-2, \mathrm{Bcl}-\mathrm{xL}$ and survivin is likely linked with lupeol's ability to induce apoptosis that is evident by increase in accumulation of lupeol-treated cells in the sub-G1 phase, processing of the initiator caspases (caspase-8 and -9), activation of the effector caspase- 3 and cleavage of PARP in HCC cells.

Our results also show that silencing SHP-2 can abrogate the inhibitory effect of lupeol on STAT3 activation, as well as abolish the antiproliferative and pro-apoptotic effects of lupeol. These findings suggest that lupeol is inhibiting tumour cell proliferation and inducing apoptosis through upregulation of SHP-2 and concomitant inhibition of STAT3 activation. The downmodulation of VEGF expression is in line with a recent report in which siRNA targeting VEGF inhibits HCC growth and tumour angiogenesis in vivo (Raskopf et al, 2008). The suppression of MMP-9 protein expression as observed here may contribute to the inhibitory effects of lupeol on the migratory and invasive potential of HCC cells. Overall, our findings indicate that lupeol interferes with several oncogenic molecules involved in tumour initiation and progression in HCC cells.

In conclusion, our data convincingly demonstrate that lupeol can negatively regulate both constitutive and inducible STAT3 activation through the suppression of upstream kinases and induction of phosphatase SHP-2 in HCC cell lines, making it a potentially effective suppressor of tumour cell survival and proliferation. Because of its potential efficacy in suppression of the deregulated STAT3 activation and low toxicity profile, lupeol may emerge as a novel candidate for HCC therapy. Additional studies in animals are required to validate these findings under in vivo settings.

\section{ACKNOWLEDGEMENTS}

This work was supported by grants from National Medical Research Council of Singapore (Grant R-184-000-211-213) to GS. KSA was supported by a grant from the Kyung Hee University in 2013 (KHU-20130546). This work was also supported by the Korea Science and Engineering Foundation (KOSEF) grant funded by the Korean Ministry of Education, Science and Technology (MoEST) (No. 2011-0006220). SJ was supported by grants from Cancer Science Institute of Singapore (R-713-006-014-271), Office of the Deputy President (Research \& Technology) (R-713-000-132133) and School of Medicine (R-713-000-132-733) at the National University of Singapore. APK was supported by grants from Singapore Ministry of Education Tier 2 (MOE 2012-T2-2-139), Academic Research Fund Tier 1 (R-184-000-228-112) and Cancer Science Institute of Singapore, Experimental Therapeutics I Program (Grant R-713-001-011-271).

\section{REFERENCES}

Baffy G, Brunt EM, Caldwell SH (2012) Hepatocellular carcinoma in non-alcoholic fatty liver disease: An emerging menace. J Hepatol 56(6): 1384-1391.
Bhutani M, Pathak AK, Nair AS, Kunnumakkara AB, Guha S, Sethi G, Aggarwal BB (2007) Capsaicin is a novel blocker of constitutive and interleukin-6-inducible STAT3 activation. Clin Cancer Res 13(10): 3024-3032.

Bromberg J, Wang TC (2009) Inflammation and cancer: IL-6 and STAT3 complete the link. Cancer Cell 15(2): 79-80.

Burke WM, Jin X, Lin HJ, Huang M, Liu R, Reynolds RK, Lin J (2001) Inhibition of constitutively active Stat3 suppresses growth of human ovarian and breast cancer cells. Oncogene 20(55): 7925-7934.

Cervello M, McCubrey JA, Cusimano A, Lampiasi N, Azzolina A, Montalto G (2012) Targeted therapy for hepatocellular carcinoma: novel agents on the horizon. Oncotarget 3(3): 236-260.

Chen RH, Chang MC, Su YH, Tsai YT, Kuo ML (1999) Interleukin-6 inhibits transforming growth factor-beta-induced apoptosis through the phosphatidylinositol 3-kinase/Akt and signal transducers and activators of transcription 3 pathways. J Biol Chem 274(33): 23013-23019.

Cormier JN, Thomas KT, Chari RS, Pinson CW (2006) Management of hepatocellular carcinoma. J Gastrointest Surg 10(5): 761-780.

Dechow TN, Pedranzini L, Leitch A, Leslie K, Gerald WL, Linkov I, Bromberg JF (2004) Requirement of matrix metalloproteinase-9 for the transformation of human mammary epithelial cells by Stat3-C. Proc Natl Acad Sci USA 101(29): 10602-10607.

Dey A, Wong E, Kua N, Teo HL, Tergaonkar V, Lane D (2008) Hexamethylene bisacetamide (HMBA) simultaneously targets AKT and MAPK pathway and represses NF-KB activity. Cell Cycle 7(23): 3759-3767.

Fuke H, Shiraki K, Sugimoto K, Tanaka J, Beppu T, Yoneda K, Yamamoto N, Ito K, Masuya M, Takei Y (2007) Jak inhibitor induces S phase cell-cycle arrest and augments TRAIL-induced apoptosis in human hepatocellular carcinoma cells. Biochem Biophys Res Commun 363(3): 738-744.

Garcia R, Bowman TL, Guillian N, Hua Y, Minton S, Muro-Cacho CA, Cox CE, Falcone R, Fairclough R, Parsons S (2001) Constitutive activation of Stat3 by the Src and JAK tyrosine kinases participates in growth regulation of human breast carcinoma cells. Oncogene 20(20): 2499-2513.

Ghosh A, Saginc G, Leow SC, Khattar E, Shin EM, Yan TD, Wong M, Zhang Z, Li G, Sung WK (2012) Telomerase directly regulates NF-אB-dependent transcription. Nat Cell Biol 14(12): 1270-1281.

Gritsko T, Williams A, Turkson J, Kaneko S, Bowman T, Huang M, Nam S, Eweis I, Diaz N, Sullivan D, Yoder S, Enkemann S, Eschrich S, Lee JH, Beam CA, Cheng J, Minton S, Muro-Cacho CA, Jove R (2006) Persistent activation of Stat 3 signaling induces Survivin gene expression and confers resistance to apoptosis in human breast cancer cells. Clin Cancer Res 12(1): 11-19.

Grivennikov SI, Karin M (2010) Dangerous liaisons: STAT3 and NF- $\kappa B$ collaboration and crosstalk in cancer. Cytokine Growth Factor Rev 21(1): $11-19$.

Ihle JN (1996) STATs: signal transducers and activators of transcription. Cell 84(3): 331-334.

Jemal A, Bray F, Center MM, Ferlay J, Ward E, Forman D (2011) Global cancer statistics. CA Cancer J Clin 61(2): 69-90.

Johnston PA, Grandis JR (2011) STAT3 signaling: anticancer strategies and challenges. Mol Interv 11(1): 18-26.

Kannaiyan R, Hay HS, Rajendran P, Li F, Shanmugam MK, Vali S, Abbasi T, Kapoor S, Sharma A, Kumar AP (2011) Celastrol inhibits proliferation and induces chemosensitization through down-regulation of NF- $\mathrm{KB}$ and STAT3 regulated gene products in multiple myeloma cells. Br J Pharmacol 164(5): 1506-1521.

Kim C, Cho SK, Kapoor S, Kumar A, Vali S, Abbasi T, Kim SH, Sethi G, Ahn KS (2013) $\beta$-Caryophyllene oxide inhibits constitutive and inducible STAT3 signaling pathway through induction of the SHP1 protein tyrosine phosphatase. Mol Carcinog; e-pub ahead of print 13 June 2013; doi:10.1002/mc. 22035.

Lee H, Herrmann A, Deng JH, Kujawski M, Niu G, Li Z, Forman S, Jove R, Pardoll DM, Yu H (2009) Persistently activated Stat3 maintains constitutive NF- $\kappa \mathrm{B}$ activity in tumors. Cancer Cell 15(4): 283-293.

Lee TK, Poon RTP, Wo JY, Ma S, Guan XY, Myers JN, Altevogt P, Yuen APW (2007) Lupeol suppresses cisplatin-induced nuclear factor- $\mathrm{\kappa B}$ activation in head and neck squamous cell carcinoma and inhibits local invasion and nodal metastasis in an orthotopic nude mouse model. Cancer Res 67(18): 8800-8809.

Lee TKW, Castilho A, Cheung VCH, Tang KH, Ma S, Ng IOL (2011a) $\mathrm{CD} 24(+)$ liver tumor-initiating cells drive self-renewal and tumor initiation through STAT3-mediated NANOG regulation. Cell Stem Cell 9(1): 50-63. 
Lee TKW, Castilho A, Cheung VCH, Tang KH, Ma S, Ng IOL (2011b) Lupeol targets liver tumor-initiating cells through phosphatase and tensin homolog modulation. Hepatology 53(1): 160-170.

Lepiller Q, Abbas W, Kumar A, Tripathy MK, Herbein G (2013) HCMV activates the IL-6-JAK-STAT3 axis in HepG2 cells and primary human hepatocytes. PLoS One 8(3): e59591.

Li F, Shanmugam MK, Chen L, Chatterjee S, Basha J, Kumar AP, Kundu TK, Sethi G (2013) Garcinol, a polyisoprenylated benzophenone modulates multiple proinflammatory signaling cascades leading to the suppression of growth and survival of head and neck carcinoma. Cancer Prev Res (Phila) 6(8): 843-854.

Li WC, Ye SL, Sun RX, Liu YK, Tang ZY, Kim Y, Karras JG, Zhang H (2006) Inhibition of growth and metastasis of human hepatocellular carcinoma by antisense oligonucleotide targeting signal transducer and activator of transcription 3. Clin Cancer Res 12(23): 7140-7148.

Newman DJ (2008) Natural products as leads to potential drugs: an old process or the new hope for drug discovery? J Med Chem 51(9): 2589-2599.

Page BD, Ball DP, Gunning PT (2011) Signal transducer and activator of transcription 3 inhibitors: a patent review. Expert Opin Ther Pat 211: 65-83.

Prasad S, Madan E, Nigam N, Roy P, George J, Shukla Y (2009) Induction of apoptosis by lupeol in human epidermoid carcinoma A431 cells through regulation of mitochondrial, Akt/PKB and NF-kappaB signaling pathways. Cancer Biol Ther 8(17): 1632-1639.

Rajendran P, Li F, Manu KA, Shanmugam MK, Loo SY, Kumar AP, Sethi G (2011) $\gamma$-Tocotrienol is a novel inhibitor of constitutive and inducible STAT3 signalling pathway in human hepatocellular carcinoma: potential role as an antiproliferative, pro-apoptotic and chemosensitizing agent. $\mathrm{Br} J$ Pharmacol 163(2): 283-298.

Rajendran P, Li F, Shanmugam MK, Kannaiyan R, Goh JN, Wong KF, Wang W, Khin E, Tergaonkar V, Kumar AP (2012) Celastrol suppresses growth and induces apoptosis of human hepatocellular carcinoma through the modulation of STAT3/JAK2 signaling cascade in vitro and in vivo. Cancer Prev Res (Phila) 5(4): 631-643.

Raskopf E, Vogt A, Sauerbruch T, Schmitz V (2008) siRNA targeting VEGF inhibits hepatocellular carcinoma growth and tumor angiogenesis in vivo. J Hepatol 49(6): 977-984.

Shanmugam MK, Rajendran P, Li F, Nema T, Vali S, Abbasi T, Kapoor S, Sharma A, Kumar AP, Ho PC (2011) Ursolic acid inhibits multiple cell survival pathways leading to suppression of growth of prostate cancer xenograft in nude mice. J Mol Med 89(7): 713-727.

Shuai K, Liu B (2003) Regulation of JAK-STAT signalling in the immune system. Nat Rev Immunol 3(11): 900-911.
Siddique HR, Mishra SK, Karnes RJ, Saleem M (2011) Lupeol, a novel androgen receptor inhibitor: implications in prostate cancer therapy. Clin Cancer Res 17(16): 5379-5391.

Siddique HR, Saleem M (2011) Beneficial health effects of lupeol triterpene: a review of preclinical studies. Life Sci 88(7-8): 285-293.

Subramaniam A, Shanmugam MK, Perumal E, Li F, Nachiyappan A, Dai X, Swamy SN, Ahn KS, Kumar AP, Tan BKH, Hui KM, Sethi G (2013) Potential role of signal transducer and activator of transcription (STAT)3 signaling pathway in inflammation, survival, proliferation and invasion of hepatocellular carcinoma. Biochim Biophys Acta 1835(1): 46-60.

Tarapore RS, Siddiqui IA, Saleem M, Adhami VM, Spiegelman VS, Mukhtar H (2010) Specific targeting of Wnt/ $\beta$-catenin signaling in human melanoma cells by a dietary triterpene lupeol. Carcinogenesis 31(10): 1844-1853.

Wang H, Lafdil F, Kong X, Gao B (2011) Signal transducer and activator of transcription 3 in liver diseases: a novel therapeutic target. Int J Biol Sci 7(5): 536-550.

Wormald S, Hilton DJ (2004) Inhibitors of cytokine signal transduction. J Biol Chem 279(2): 821-824.

Xu D, Qu C-K (2008) Protein tyrosine phosphatases in the JAK/STAT pathway. Front Biosci 13: 4925-4932.

Yang F, Brown C, Buettner R, Hedvat M, Starr R, Scuto A, Schroeder A, Jensen M, Jove R (2010) Sorafenib induces growth arrest and apoptosis of human glioblastoma cells through the dephosphorylation of signal transducers and activators of transcription 3. Mol Cancer Ther 9(4): 953-962.

Yu C-L, Meyer DJ, Campbell GS, Larner AC, Carter-Su C, Schwartz J, Jove R (1995) Enhanced DNA-binding activity of a Stat3-related protein in cells transformed by the Src oncoprotein. Science 269(5220): 81-83.

Yue P, Turkson J (2009) Targeting STAT3 in cancer: how successful are we? Expert Opin Invest Drugs 18(1): 45-56.

Zhang Q, Raghunath PN, Xue L, Majewski M, Carpentieri DF, Odum N, Morris S, Skorski T, Wasik MA (2002) Multilevel dysregulation of STAT3 activation in anaplastic lymphoma kinase-positive T/null-cell lymphoma. J Immunol 168(1): 466-474.

This work is published under the standard license to publish agreement. After 12 months the work will become freely available and the license terms will switch to a Creative Commons AttributionNonCommercial-Share Alike 3.0 Unported License.

Supplementary Information accompanies this paper on British Journal of Cancer website (http://www.nature.com/bjc) 